\title{
EXPECTED ADVANTAGES AND DISADVANTAGES OF ONLINE LEARNING: PERCEPTIONS FROM COLLEGE STUDENTS WHO HAVE NOT TAKEN ONLINE COURSES
}

\author{
MelodyW. Alexander, Ball State University, malexander@bsu.edu \\ Allen D. Truell, Ball State University, atruell@bsu.edu \\ Jensen J. Zhao, Ball State University, jzhao@bsu.edu
}

\begin{abstract}
Online courses and programs are continuing to grow in post-secondary education, and many information systems professors are becoming involved in planning and implementing online offerings. While designing online courses, student input is of great value. The purpose of this study was to document college students' expectations of the advantages and disadvantages of taking courses online. A further analysis identified any differences in perceptions between genders. A total of 420 college students in information systems courses completed an online survey reporting their perceptions of what they expected would be the advantages and disadvantages of taking online courses. These students had no previous experience with taking online courses. Results of the study provide insight to information systems educators as they become involved in designing courses in the online environment. Areas of further research for information systems educators are suggested.
\end{abstract}

Keywords: Information Systems, Online Courses, Student Perceptions

\section{INTRODUCTION}

Online courses and degree program offerings are continuing to grow in post-secondary education. As documented by Allen and Seaman [1] in the Eighth Annual Sloan Survey of Online Education, more than 5.6 million students took an online course during the fall of 2009. Many educators are becoming involved in the planning and converting of traditional courses into an online format. The type of class as well as the instructor can also influence a students' online experience, and instructor training for online courses is essential $[13,16]$.

When preparing online courses, student input in regard to experience and expectations is of great value. Researchers have documented student experiences with online courses and found that several variables affect course completion $[2,6,8]$. Predicting patterns of online student effort, performance and success have been important areas of study [5, $9,12,14]$. Implementing new online strategies then assessing and evaluating course offerings needs to be ongoing [11]. Designing and refining online course delivery methods will continue to be a focus of administrators and instructors.

Online courses provide opportunities for students all over the world. Students in online classes can work together with others from various places to share diverse opinions and collaborate in solving problems [4]. Yet even with numerous benefits, online educators and administrators have various issues to overcome. Although many students have reported positive experiences with online courses, negative experiences have also been conveyed [6, 14]. While course evaluations indicate students would rather take online versus traditional courses, students report online courses require more time and commitment, and may have limited communication with fellow students [4, 9]. Academic dishonesty is another serious issue and ensuring the person doing the work is (in fact) the student enrolled in the class is critical [4]. Identifying safeguards to prevent dishonesty is an area which will need to be addressed in online course designs.

Through increases in online enrollments, colleges and universities recognize many students are choosing to take online over traditional courses. In 2010 almost thirty percent of students in higher education took an online course 


\section{Issues in Information Systems}

Volume 13, Issue 2, pp. 193-200, 2012

[1]. As discussed by Blakely [4] hectic lives, economic situations, work schedules and family responsibilities are some of the reasons students elect to take courses online. Other benefits for taking online over traditional courses are due to lower costs, time efficiency and convenience to work around personal schedules $[4,10]$. As there is no projection of when this growth might end, researching trends in online enrollments will provide valuable marketing information to all levels of education $[1,2]$.

\section{NEED FOR THE STUDY}

As online enrollments continue to rise, research in this area will remain an important area of study. As stated by Dobbs, Waid, \& Carmen [6] research identifying students' perceptions of online learning is limited. Although many post-secondary instructors are involved in designing online courses, as indicated by Beard, Harper, and Riley [3] many of these offerings are designed without needed student contributions. In addition, research involving student perceptions of online courses has typically concentrated on students who have had actual experience with online courses [6]. Therefore, this study was conducted to identify the perceptions of students in traditional information systems courses (who had no experience with online courses) in relation to their expectations of the advantages and disadvantages of taking online courses.

Several researchers have examined gender variables in online courses and reported differences that warrant further study [7, 12, 15]. Aragon and Johnson [2] found that as compared with males, more females had enrolled and completed an online course. Conducting further research in gender differences to determine why females and males differ in online course enrollment was suggested [2]. Therefore, this study will also identify any differences in perceptions of the expected advantages and disadvantages based on gender.

\section{PURPOSE}

Becoming proficient with the methods to educate students through online courses is essential for colleges and universities that are keeping up-to-date with market demands. One way to address proficiency is by studying the expectations of potential online learners and to implement strategies to best meet the needs of the online learner.

The purpose of this study, therefore, was to document college students' perceptions of the expected advantages and disadvantages of taking online courses. A secondary purpose was to identify if any differences in perceptions exist between genders. To address this purpose, answers to the following research questions were investigated:

1. What are college students' perceptions of the expected advantages and disadvantages of taking online courses?

2. Are there statistically significant differences in college students' perceptions of the expected advantages and disadvantages of taking online courses based on gender?

\section{PROCEDURES}

The procedures used to conduct the study are outlined in the following section and include a description of the study participants, instrument, data collection, and data analysis.

\section{Participants}

The participants for this study consisted of students enrolled in eleven sections of an information systems course offered at a mid-sized, Midwestern university. As required by Institutional Review Board (IRB) protocol, only students who were willing volunteers participated in the study. After explaining the purpose of the study, a total of 420 students volunteered to participate. 


\section{Issues in Information Systems}

Volume 13, Issue 2, pp. 193-200, 2012

\section{Instrument}

As no instrument was found that directly addressed the study objectives, a survey instrument was developed by the researchers. The survey instrument was based on input from 43 students from an information systems class who provided reasons for taking (or not taking) online courses. Drawing from the researchers 'experiences with distance education (independent learning) courses, the survey instrument included two sections: 1). advantages of taking online courses over traditional courses, and 2). disadvantages of taking online courses over traditional courses. The survey consisted of three demographic questions (gender, age, and class level), followed by ten advantages and ten disadvantages. Approximately three minutes was needed to complete the survey.

Instrument Validation. The survey instrument was reviewed for validity by a 9-member panel of experts. The panel of experts included information systems researchers, information systems faculty (both traditional and distance educators), and distance education administrators. The panel's evaluation indicated that the survey met the researchers' stated objectives.

Instrument Clarification. Clarity of the instrument's directions and individual questions was pilot tested with a volunteer group of 33 students from an advanced information systems course. Since no difficulties were reported by the pilot group, no changes in wording or length were made to the survey.

\section{Data Collection}

During the last week of the fall semester, students enrolled in eleven sections of an information systems course were asked to complete an online survey regarding their perceptions of the expected advantages and disadvantages of taking courses online. It was explained to students during survey administration that participation in this study was voluntary, anonymous, and would not have an impact on their final course grade. A total of 420 students volunteered to participate in the study.

\section{Data Analysis}

In accordance with the university's guidelines, all identifiers were removed before statistical analysis was conducted. Frequencies and percentages were calculated to provide a demographic profile of the participants and to document their perceptions of the expected advantages and disadvantages of taking online courses. Gender differences between perceptions were identified by running Pearson's Chi Square test. All tests of significance were determined at the .05 alpha levels.

\section{FINDINGS}

After providing a demographic profile of the respondents, an analysis of the findings addressing the two research questions is presented. This analysis includes perceptions of the expected advantages and disadvantages of taking online courses as perceived by students who had no previous online course experience.

\section{Participant Demographic Profile}

A total of 420 students enrolled in eleven sections of an information systems course participated in this study. Gender was represented by 245 males (59\%) and 168 females (41\%). Age ranges included 80 (19\%) 18-year-olds, $125(30 \%)$ 19-year-olds, 98 (23\%) 20-year-olds, 70 (17\%) 21-year olds, and $47(11 \%)$ aged 22 and over. There were $162(39 \%)$ freshman, 121 (29\%), sophomores and 137 (33\%) upper classmen (juniors and seniors). 


\section{Issues in Information Systems}

Volume 13, Issue 2, pp. 193-200, 2012

Table 1. Participant Demographic Profile

\begin{tabular}{lcc}
\hline Variable & $\begin{array}{c}\text { Frequency } \\
(\boldsymbol{N = 4 2 0})^{\boldsymbol{a}}\end{array}$ & $\begin{array}{c}\text { Valid } \\
\text { Percent }\end{array}$ \\
\hline Gender & & \\
Male & 245 & 59.3 \\
Female & 168 & 40.7 \\
& & \\
Age range & & \\
18 & 80 & 19.0 \\
19 & 125 & 29.8 \\
20 & 98 & 23.3 \\
21 & 70 & 16.7 \\
$22+$ & 47 & 11.2 \\
& & \\
Class level & & 38.6 \\
Freshman & 162 & 28.8 \\
Sophomore & 121 & 32.6 \\
Junior/Senior & 137 & \\
\hline
\end{tabular}

${ }^{a}$ Some respondents elected not to report gender.

\section{Research Question One}

Research question one was asked to document student perceptions of the expected advantages and disadvantages of taking online courses. Frequencies and percentages for the expected advantages and disadvantages are presented below.

Perceptions of the Expected Advantages of Online Courses. The two main advantages of taking online courses as reported by over eighty percent of the participants were convenience (i.e. dress, travel) and flexibility (i.e. time, pace). Approximately seventy percent reported not having to sit through lectures, ability to view/review lectures as needed and lower costs (i.e. parking, food) would be expected advantages of taking online courses. Almost sixty percent reported advantages of taking online courses would be less stress in relation to getting to class on time and finding parking; not having to deal with other students disrupting class; and not having to wait for other students (asking questions) who work at a slower pace. Nearly forty percent indicated not working in teams and less interaction with other students would be advantages of taking online courses. 


\section{Issues in Information Systems}

Volume 13, Issue 2, pp. 193-200, 2012

Table 2. Perceptions of the Expected Advantages of Online Courses

\begin{tabular}{lcc}
\hline Expected Advantages & $\begin{array}{c}\text { Frequency } \\
(\mathbf{N = 4 2 0})\end{array}$ & $\begin{array}{c}\text { Valid } \\
\text { Percent }\end{array}$ \\
\hline & & \\
Convenience (dress, travel) & 355 & 84.5 \\
Flexibility (time, pace) & 354 & 84.3 \\
Don't have to sit through classroom lectures & 294 & 70.0 \\
Ability to view/review lecture videos as needed & 287 & 68.3 \\
Lower costs (parking, food) & 284 & 67.6 \\
Less stress (to be on time, find parking) & 245 & 58.3 \\
Don't have to deal with other students disrupting class & 238 & 56.7 \\
Don't have to wait for other students who work at a slower pace & 231 & 55 \\
Don't have to work in class teams & 167 & 39.8 \\
Less interaction with other students & 166 & 39.5 \\
\hline
\end{tabular}

Perceptions of the Expected Disadvantages of Online Courses. The three main disadvantages of taking online courses as reported by approximately seventy percent of the participants were the likelihood of procrastinating, understanding content when not face-to-face with the instructor and more self-discipline for reading and learning. Over fifty percent reported the likelihood of misunderstanding directions, stress when trying to contact instructor, technology issues and the likelihood of computer-related distractions (such as looking at Facebook) would be disadvantages for taking online courses. Around forty percent reported expected disadvantages of online courses would be increased use of email, difficulty in meeting classmates and ease of cheating by other students.

Table 3. Perceptions of the Expected Disadvantages of Online Courses

\begin{tabular}{lcc}
\hline Expected Disadvantages & $\begin{array}{c}\text { Frequency } \\
(\mathbf{N = 4 2 0})\end{array}$ & $\begin{array}{c}\text { Valid } \\
\text { Percent }\end{array}$ \\
\hline More likely to procrastinate & 292 & 69.5 \\
Harder to understand content when not face-to face with instructor & 290 & 69.0 \\
Requires more self-discipline for reading and learning & 289 & 68.8 \\
More likely to misunderstand directions & 225 & 53.6 \\
More stressful trying to reach instructor when help is needed & 220 & 52.4 \\
More stress related to technology issues & 217 & 51.7 \\
More computer-related distractions (Facebook, etc.) & 212 & 50.5 \\
Requires increased use of email & 201 & 47.9 \\
Harder to meet classmates for possible friendship & 185 & 44.0 \\
Easier for other students to cheat & 163 & 38.8 \\
\hline
\end{tabular}

\section{Research Question Two}

Research question two sought to identify any significant differences in student perceptions of the expected advantages and disadvantages of taking online courses based on gender. To test for differences between the two groups, Pearson's Chi-Square was run. When comparing the top ten advantages of online course perceptions between genders, four areas of significant differences were found. When comparing the top ten disadvantages of online course perceptions between genders, five areas of significant differences were found. 


\section{Issues in Information Systems}

Volume 13, Issue 2, pp. 193-200, 2012

Gender Differences in Perceptions of the Expected Advantages of Online Courses. In nine of the top ten advantages of taking an online course, females perceived these advantages would be higher than males. In four areas, these differences were significant. Females perceived that advantages of: 1). convenience; 2). flexibility; 3 ). not having to deal with other students disrupting class, and 4). not having to wait for slower students (asking questions) who work at a slower pace would be significantly more of an expected advantage of taking online courses over face-to-face courses as compared to males.

Table 4. Gender Differences in Perceptions of the Expected Advantages of Online Courses

\begin{tabular}{lccccc}
\hline Expected Advantages & $\begin{array}{c}\text { Male } \\
\text { Valid } \\
\text { Percent }\end{array}$ & $\begin{array}{c}\text { Female } \\
\text { Valid } \\
\text { Percent }\end{array}$ & $\begin{array}{c}\text { Chi- } \\
\text { Square }\end{array}$ & $\boldsymbol{d f}$ & $\boldsymbol{p}$ \\
\hline Convenience (dress, travel) & & & & & \\
Flexibility (time, pace) & 81.5 & 88.6 & 3.832 & 1 & $.050^{*}$ \\
Don't have to sit through classroom lectures & 81.1 & 89.8 & 5.282 & 1 & $.016^{*}$ \\
Ability to view/review materials and videos as needed & 68.3 & 70.7 & .256 & 1 & .613 \\
Lower costs (parking, food) & 65.4 & 71.9 & 1.879 & 1 & .170 \\
Less stressful (to be on time, find parking) & 65.8 & 69.5 & .589 & 1 & .443 \\
Don't have to deal with other students disrupting class & 59.3 & 56.3 & .359 & 1 & .549 \\
Don't have to wait for other students who work at a slower pace & 52.3 & 62.9 & 4.536 & 1 & $.033^{*}$ \\
Don't have to work in class teams & 51.0 & 60.5 & 3.570 & 1 & .059 \\
Less interaction with other students & 35.8 & 45.5 & 3.894 & 1 & $.048^{*}$ \\
\hline
\end{tabular}
$* p<.05$.

Gender Differences in Perceptions of the Expected Disadvantages of Online Courses. In eight of the top ten disadvantages of taking an online course, females perceived these disadvantages would be higher than males. In five areas, these differences were significant. Females perceived that disadvantages of: 1). understanding content when not face-to face with the instructor; 2). self-discipline for reading and learning; 3 ). stress in trying to reach instructor when help is needed; 4). stress related to technology issues; and 5). ease of cheating by other students to cheat would be significantly more of an expected disadvantage of taking online courses over face-to-face courses as compared to males.

Table 4. Gender Differences in Perceptions of the Expected Disadvantages of Online Courses

\begin{tabular}{lrrrrr}
\hline Expected Disadvantages & $\begin{array}{c}\text { Male } \\
\text { Valid } \\
\text { Percent }\end{array}$ & $\begin{array}{c}\text { Female } \\
\text { Valid } \\
\text { Percent }\end{array}$ & $\begin{array}{c}\text { Chi- } \\
\text { Square }\end{array}$ & $\boldsymbol{d f}$ & $\boldsymbol{p}$ \\
\hline More likely to procrastinate & 66.7 & 74.4 & 2.823 & 1 & .093 \\
Harder to understand content when not face-to face with instructor & 63.8 & 76.8 & 7.861 & 1 & $.005^{*}$ \\
Requires more self-discipline for reading and learning & 64.2 & 74.4 & 4.785 & 1 & $.029^{*}$ \\
More likely to misunderstand directions & 51.0 & 56.0 & .967 & 1 & .325 \\
More stressful trying to reach instructor when help is needed & 46.9 & 58.3 & 5.187 & 1 & $.023^{*}$ \\
More stress related to technology issues & 46.1 & 60.7 & 8.511 & 1 & $.004^{*}$ \\
More computer-related distractions (Facebook, etc.) & 48.1 & 53.0 & .926 & 1 & .336 \\
Requires increased use of email & 47.7 & 47.0 & .020 & .1 & .887 \\
Harder to meet classmates for possible friendship & 44.4 & 43.5 & .040 & 1 & .842 \\
Easier for other students to cheat & 34.6 & 45.2 & 4.319 & 1 & $.038^{*}$ \\
\hline
\end{tabular}

$* p<.05$. 


\section{Issues in Information Systems}

Volume 13, Issue 2, pp. 193-200, 2012

\section{LIMITATIONS}

When interpreting the results of the findings of this study it should be noted that following IRB protocol, only students who were willing volunteers participated. The student participants were enrolled in traditional information systems courses at a mid-sized, Midwestern university and had no prior experience with online courses. The following conclusions were drawn with these limitations in mind.

\section{CONCLUSIONS AND IMPLICATIONS}

Research question one documented student perceptions of the expected advantages and disadvantages of taking courses online. The convenience factors of not having to pay attention to dress, worry about how to get to class (car issues), or dealing with bad weather was rated as the main advantage of taking courses online. Flexibility was also rated highly, as the expectation of being able to work on the course at your own time and pace was seen as quite desirable. As most classroom teachers' would anticipate, another advantage perceived by a large number of students was not having to sit through lectures and being able to view/review lectures as needed. Somewhat unanticipated, however, was the high number of students who expected that a major advantage of online courses was not having to deal with other students disrupting class and not having to deal with other students asking questions. Females were more likely to rate expected advantages of taking online courses as higher than males, which could play a part in online enrollment. Information systems faculty and advisors should use this information not only to strengthen their online courses, but their traditional courses as well.

The main disadvantages of taking online courses were perceived as the likelihood of procrastinating, not understanding content when not face-to-face with the instructor and more self-discipline for reading and learning. Misunderstanding assignment directions, trying to contact the instructor for help, and technology issues were all reported as potentially frustrating and stressful disadvantages of online learning. In addition, many students indicated that using the computer for other non-related course activities, such as Facebook, while working on the course would be a drawback. This comes as no surprise to teachers in traditional classrooms who are continually reminding students to get off Facebook, but it is surprising that students also realize this is a major distraction. Other concerns included the increased use of communicating through email and ease of cheating by other students.

As with the advantages, females perceived some expected disadvantages would be significantly more of a disadvantage of taking online courses when compared with males. Information systems faculty and advisors need to address these perceived disadvantages by taking steps to ensure these concerns are minimized.

Traditional students enter the college environment with beliefs or expectations about online learning that may or may not be correct. As more and more students opt for taking courses online, information systems educators need to stress the requirements for successful online course completion. Although as results of this study show online courses are perceived as having many benefits, these types of courses may not fit a students' learning style. The amount of work and time required to succeed in on online course may not be understood by students. Before enrolling in an online course, students need to have realistic expectations and be aware of the unique requirements needed to succeed in an online class.

\section{RECOMMENDATIONS FOR FURTHER RESESARCH}

Based on the findings from this study, the following recommendations for additional research are offered.

1. Since online courses will be part of many higher educations' offerings, it is important to monitor students' expectations. This study should be replicated in three years to identify any changes in perceptions of the advantages and disadvantages of taking online classes

2. As this study focused on students who were enrolled in traditional information systems courses, further research should be conducted with students enrolled in online information systems courses. 


\section{Issues in Information Systems}

Volume 13, Issue 2, pp. 193-200, 2012

3. Since this study found several areas of perceived disadvantages of taking online courses, further research should focus on this area.

4. As this study focused on the demographic variable of gender, other variables including class level and age should be studied.

\section{REFERENCES}

1. Allen, I. E., \& Seaman, J. (Nov 2010). Class differences: Online education in the United States, 2010. Retrieved from http://sloanconsotrium.org/publications/survey/class_differences

2. Aragon, S. R., \& Johnson, E. S. (Jul 2008). Factors influencing completion and noncompletion of community college online courses. American Journal of Distance Education, 22(3), 146-158.

3. Beard, L. A., Harper, C., \& Riley G. (Nov/Dec 2004). Online versus on-campus instruction: Student attitudes \& perceptions. TechTrends: Linking Research \& Practice to Improve Learning, 48(6), $29-31$.

4. Blakey, L. (2010). The proliferation, pitfalls, and power of online education. Cases on Distance Delivery and Learning Outcomes: Emerging Trends and Programs. Ed. Deb Gearhart. Hershey, PA: Information Science Reference, 167-189.

5. Dibiase, D., \& Kidwai, K. (Aug 2012). Wasted on the young? Comparing the performances and attitudes of younger and older US adults in an online class on geographic information. Journal of Geography in Higher Education, 34 (3), 299-326.

6. Dobbs, R. D., Waid, C. A. \& del Carmen, A. ((2009). Students' perceptions of online courses: The effect on online course experience. The Quarterly Review of Distance Education, 10(1), 9-26.

7. Groneman Hite, N. (2100). Research in Online Education. Online Business Education, NBEA Yearbook, 49, 1628.

8. Harrell, I. \& Bower, B. (2011). Student characteristics that predict persistence in community college online courses. American Journal of Distance Education, 25(3), 178-191.

9. Horspool, A. (Feb 2012). Applying the scholarship of teaching and learning: Student perceptions, behaviours and success online and face-to-face. Assessment \& Evaluation in Higher Education, 37(1), 73-88.

10. Nelson, J. A. (Oct 2008). Advantages of online education. Home Health Care Management \& Practice, 20(6), 501-502.

11. Perrault, H. (2010). Administrative support and evaluation of online education. Online Business Education, NBEA Yearbook, 49, 180-191.

12. Price, L. (2006). Gender differences and similarities in online courses: Challenging stereotypical views of women. Journal of Computer Assisted Learning, 22, 349-359.

13. Robles, M. (2010). History of online education and its impact on business education. Online Business Education, NBEA Yearbook, 49, 1-15.

14. Weimer, M. (Mar 2012) Online or In Class? Teaching Professor, 26 (3), 7.

15. Yang, Y. Cho, Y., Mathew, S., \& Worth, S. (Aug 2011). College student effort expenditure in online versus face-to-face courses: The role of gender, team learning orientation, and sense of classroom community. Journal of Advanced Academics (22)4, 619-638.

16. Zeliff, N. (2010). Delivery options of online education. Online Business Education, NBEA Yearbook, 49, 68-81. 